http://jmscr.igmpublication.org/home/ ISSN (e)-2347-176x ISSN (p) 2455-0450

crossref DOI: https://dx.doi.org/10.18535/jmscr/v7i12.03

Journal Of Medical Science And Clinical Research

\title{
Study of progression of diabetic retinopathy in pregnancy \& its correlation with glycemic control in a tertiary health care center in state of Odisha
}

Authors

\section{Dr Debasish Hota ${ }^{1}$, Dr Suresh Chandra Swain², Prof. (Dr) Jayant Kumar Panda ${ }^{3}$, Dr Deepak Choudhury ${ }^{4}$, Prof. (Dr) Prabhat Kumar Padhi ${ }^{5}$, Prof. (Dr) Maya Padhi ${ }^{6}$, Dr Nikita Dash ${ }^{7}$}

\author{
${ }^{1} \mathrm{MD}$ (Medicine), ${ }^{2}$ Associate Professor, Dept. of Ophthalmology, SCB Medical College, Cuttack \\ ${ }^{3}$ Professor, Dept. of Medicine, SCB Medical College, Cuttack, ${ }^{4}$ MS (Ophthalmology) \\ ${ }^{5}$ Professor, Dept. of Medicine, SCB Medical College, Cuttack \\ ${ }^{6}$ Professor, Dept. of O\&G, SCB Medical College, Cuttack \\ ${ }^{7}$ Senior Resident, AIIMS, Bhubaneswar
}

\begin{abstract}
Purpose: The objective of this study is to assess the rapidity of progression of retinopathy in pregnant diabetic women during gestational period with correlation with glycemic control.

Materials \& Methods: This was a prospective observational study of patients admitted/ visited to the department of Medicine, Endocrinology, Ophthalmology \& Obstetrics \& Gynecology in a tertiary health care system in State of Odisha during January 2016 to December 2017. The study included total 50 pregnant with diabetes vs 50 non-pregnant diabetes for progression of retinopathy during their gestational period.

Results: At the end of study, 32.5\% of cases in the study group showed progression of retinopathy staging during pregnancy as compared to $14 \%$ in non-pregnant women. The glycosylated hemoglobin, duration of diabetes, current age was evaluated as risk factors for progression of diabetic retinopathy.

Conclusion: Pregnancy, level of glycemia $(\mathrm{HbAlc})$ \& age are risk factors for acceleration of Retinopathy progression.
\end{abstract}

Keywords: Pregnancy, Diabetic retinopathy, HbAlc.

\section{Introduction}

Diabetes mellitus is a disorder in which the level of blood glucose is persistently raised above the normal range. ${ }^{1} \mathrm{DM}$ is a chronic disorder with multiorgan involvement having many microvascular and macrovascular complications. ${ }^{2}$ Microvascular complications are caused by chronic hyperglycaemia, whereas macrovascular complications are caused by both chronic hyperglycaemia and the consequences of insulin resistance. ${ }^{3}$ Diabetic Retinopathy (DR) is the most common microvascular complication of Diabetes Mellitus (DM). Pregnancy is a major risk factor for the progression of Retinopathy \& is definitely associated with increased prevalence \& severity of Retinopathy compared to non-pregnant diabetic women. ${ }^{4}$ The risk factors for the progression of Retinopathy in pregnancy are severity of Retinopathy at conception, glycemic control, duration of diabetes, age of pregnant women, hypertension. Pregnancy itself found to be an independent risk factor. ${ }^{5}$ 
The objective of this study is to assess the rapidity of progression of retinopathy in pregnant diabetic women during gestational period with correlation with glycemic control.

\section{Materials \& Methods}

This study conducted as prospective observational study of patients admitted/visited to the Department of Medicine, Endocrinology, Ophthalmology \& Obstetrics \& Gynecology in a tertiary health care system during January 2016 to December 2017.The study includes total 50 pregnant with diabetes vs 50 non-pregnant diabetes for progression of Retinopathy during their gestational period.

\section{Inclusion Criteria}

- Diabetic pregnant women of either 5 years or more duration

- Any type (type-1/type-2/other type of known diabetic women)

\section{Exclusion Criteria}

- Other causes of Retinopathy/Prior retinal diseases

- Gestational diabetes

\section{Study Design}

In this study minimum 50 numbers of pregnant diabetic of either 5 years or more duration are selected as case. These pregnant ladies are evaluated for glycemic status (FBS, PPBS, HbA1C), any Retinopathy changes by direct \& Indirect Ophthalmoscopy, fundus photography as soon as pregnancy is confirmed by Urine pregnancy test.

\section{Diagnosis \& Staging of Retinopathy}

For retinopathy changes evaluation by direct \& Indirect Ophthalmoscopy, fundus photography was done for any fresh changes in Retinopathy during each ANC. Depending upon changes/development of Retinopathy, patients are staged according to International Clinical Diabetic Retinopathy Disease Severity scale for DR.(No apparent retinopathy, mild NPDR, moderate NPDR, severe NPDR, PDR).

\section{Observation}

Table-1 No. of Cases with Retinopathy at Baseline

\begin{tabular}{|l|c|c|c|}
\hline \multirow{2}{*}{} & \multicolumn{2}{|c|}{ DIABETIC PATIENT } & \multirow{2}{*}{ TOTAL } \\
\cline { 2 - 3 } & PREGNANT & NON-PREGNANT & 21 \\
\hline $\mathrm{R}^{+}$ & $9(18 \%)$ & $12(24 \%)$ & 79 \\
\hline $\mathrm{R}^{-}$ & $41(82 \%)$ & $38(76 \%)$ & 100 \\
\hline TOTAL & 50 & 50 & \\
\hline \hline
\end{tabular}

At baseline only $18 \%$ have retinopathy in diabetic pregnant as compared to $24 \%$ of non-pregnant.

Table-2 No. of Cases with Retinopathy at Last Visit

\begin{tabular}{|l|c|c|c|}
\hline \multirow{2}{*}{} & \multicolumn{2}{|c|}{ DIABETIC PATIENT } & \multirow{2}{*}{ TOTAL } \\
\cline { 2 - 3 } & PREGNANT & NON-PREGNANT & 37 \\
\hline $\mathrm{R}^{+}$ & $22(55 \%)$ & $15(30 \%)$ & 53 \\
\hline $\mathrm{R}^{-}$ & $18(45 \%)$ & $35(70 \%)$ & 90 \\
\hline TOTAL & 40 & 50 & \\
\hline
\end{tabular}

At the end of pregnancy, 10 patients could not visit for follow up. At last visit $55 \%$ cases had retinopathy as compared to $30 \%$ in the control group. On comparison at the end point of study, progression of retinopathy in pregnant diabetic patient is much higher as compared to other.

$\mathrm{R}$ - (No retinopathy) $\mathrm{R}+$ (retinopathy) D (lost to follow up) 
At start of study $82 \%$ of pregnant women had no Retinopathy as compared to $76 \%$ of cases in nonpregnant group. At the end of study, $45 \%$ of pregnant women had no retinopathy but $55 \%$ have various stages of Retinopathy as compared to $30 \%$ in the control group.

Table N0.3. Status of DR at End Point of Study

\begin{tabular}{|l|c|c|c|}
\hline \multicolumn{2}{|c|}{} & \multicolumn{2}{c|}{ DIABETIC } \\
\cline { 3 - 4 } \multicolumn{2}{|c|}{} & PREGNANT & NONPREGNANT \\
\hline TATUS OF DR & $\begin{array}{c}\text { NO } \\
\text { PREGRESS }\end{array}$ & $27(67.5 \%)$ & $47(94 \%)$ \\
\cline { 2 - 4 } & PROGRESS & $13(32.5 \%)$ & $3(6 \%)$ \\
\hline \multicolumn{2}{|c|}{ Total } & 40 & 50 \\
\hline \hline
\end{tabular}

At the end point of study, $32.5 \%$ of the Cases in the study group showed progression of retinopathy staging during pregnancy as compared to $6 \%$ in non-pregnant women. So we concluded that pregnancy is a risk factor for acceleration of retinopathy progression.

Table No.4 Risk Correlation between Retinopathy and HbA1C (Study Group)

\begin{tabular}{|c|c|c|c|c|c|}
\hline & & \multicolumn{2}{|c|}{ MEAN HbAIC } & \multirow{2}{*}{ Total } & \multirow{2}{*}{$\mathrm{P}$ value } \\
\hline & & $<8$ & $>8$ & & \\
\hline \multirow[t]{2}{*}{ Status of DR } & $\begin{array}{c}\text { NO } \\
\text { PROGRESS }\end{array}$ & $24(80 \%)$ & $3(30 \%)$ & 27 & \multirow[t]{2}{*}{0.043} \\
\hline & PROGRESS & $6(20 \%)$ & $7(70 \%)$ & 13 & \\
\hline \multicolumn{2}{|c|}{ Total } & 30 & 10 & 40 & \\
\hline
\end{tabular}

Among diabetic pregnant, patient having $\mathrm{HbA} 1 \mathrm{C}$ $<8$ ( $80 \%$ show no progression of retinopathy). But HbA1C $>8 \quad(70 \%$ shows progression of retinopathy). So there is significant risk of progression in relation to long term glycemic control.

Graph 1 shows duration of DM Vs retinopathy progression.

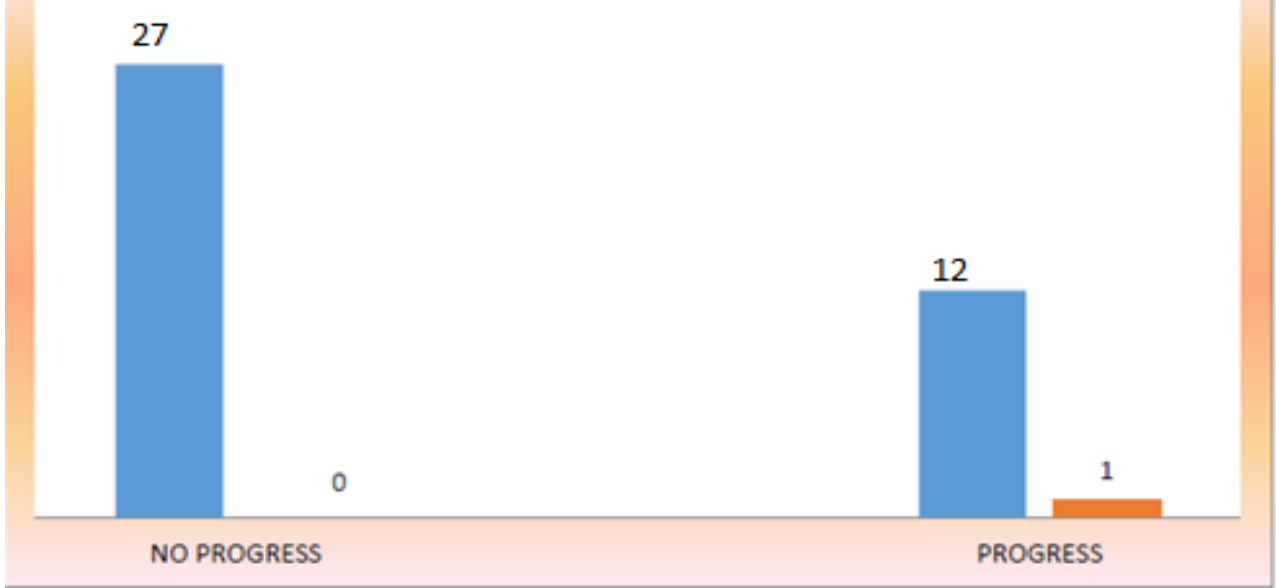

Graph 1: Duration of DM Vs retinopathy progression.

$\mathrm{P}$ value was 0.143 . As the $\mathrm{p}$ value $>0.05$, so there is no significant difference in term of duration diabetes in both group, because of small sample size, very few pregnant cases more than 10 years. 
Table No.5 Age vs Retinoapthy Progression

(Study Group)

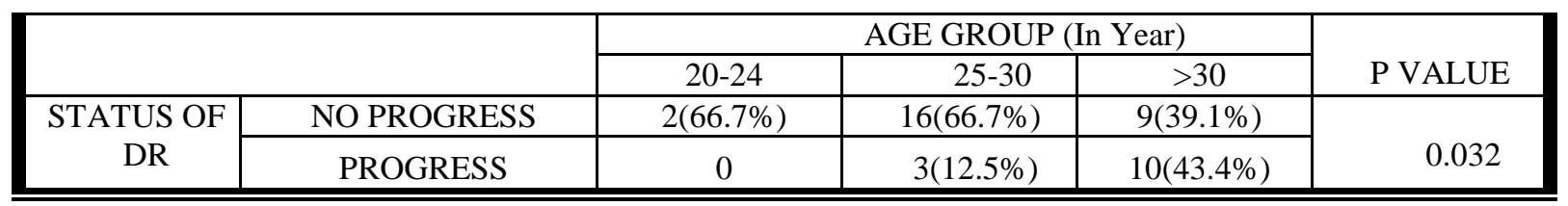

Among age group 25-30 years \& more than 30 years progression of retinopathy occurs more frequently as age progresses $(43.4 \%$ in age group> 30 years \& $12.5 \%$ age group $25-30$ years). As $\mathrm{p}<0.05$, so more is age more likely there is progression of retinopathy during pregnancy.

Graph 2 shows BMI Vs retinopathy progression.

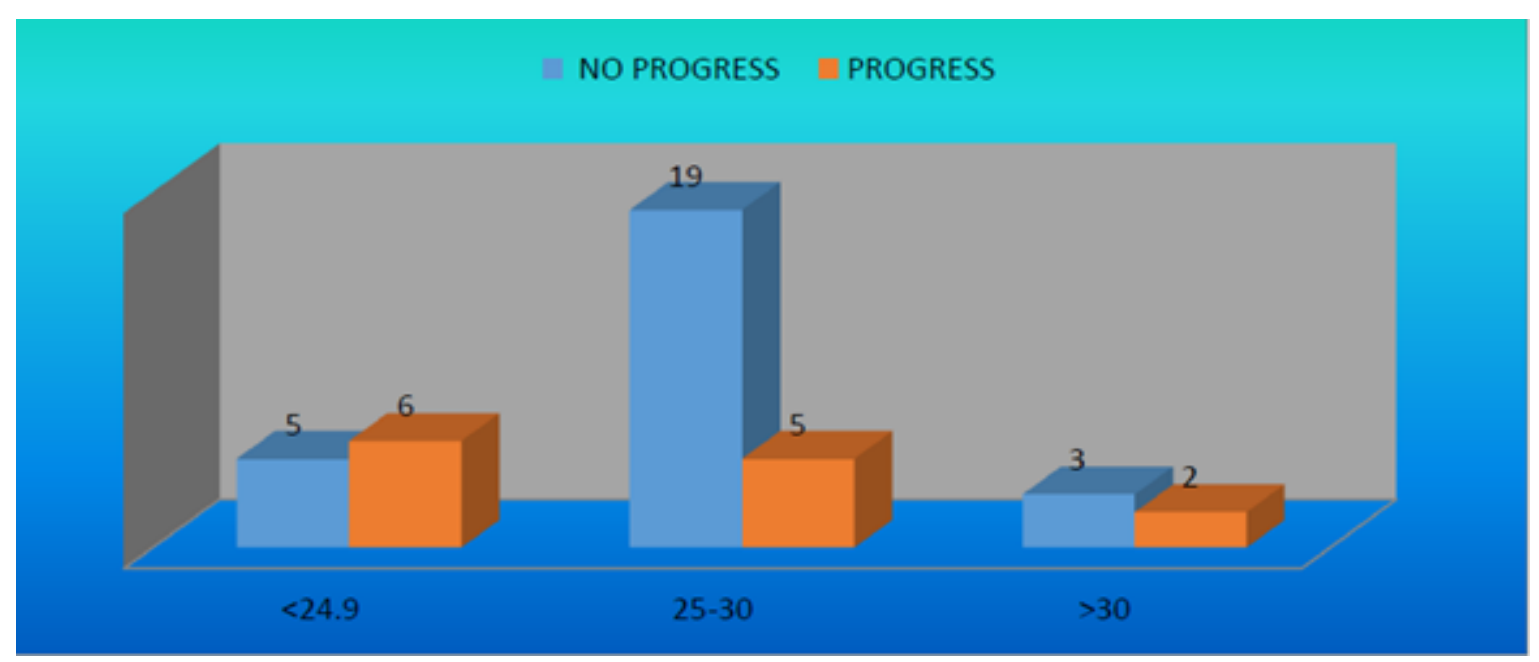

Graph 2: BMI Vs retinopathy progression.

$\mathrm{P}$ value was 0.109 . As $\mathrm{p}>0.05$, BMI \& progression of retinopathy is non-significant.

\section{Discussion}

All the above data collected as per study proforma $\&$ analysed by SPSS 21 using chi-square test \& unpaired $\mathrm{t}$ test to show significant $\mathrm{P}$ value.

At base line, $82 \%$ has no Retinopathy, $10 \%$ had mild Retinopathy \& $8 \%$ had moderate degree. As the pregnancy proceeds more chance or progression depended upon base line DR \& higher grade of Retinopathy. Sampson MJ et al study showed that Progression was more significant in women with moderate and severe forms of retinopathy compared to women with mild or no retinopathy at conception. ${ }^{6}$ Maximum progression occurred in end or $2^{\text {nd }}$ trimester or $3^{\text {rd }}$ trimester. At end of study $30 \%$ had mild Retinopathy \& $12 \%$ had moderate Retinopathy. $32.5 \%$ had progression of retinopathy staging during pregnancy as compared to $6 \%$ in non-pregnant diabetic women. PS Mallika et al although pregnancy does not have any long term effect on DR, progression of retinopathy changes occur in $50 \%-70 \%$ of cases. $^{7}$ Pregnant women having $\mathrm{HbA} 1 \mathrm{C}<8,20 \%$ showed progression of retinopathy, whereas patients having $\mathrm{HbA} 1 \mathrm{C}>8,70 \%$ showed progression of retinopathy. $\mathrm{P}<0.043$ which significant. So there is strong correlation between glycemic control \& retinopathy progression. Mathiesen ER et a lstated that low incidence of severe progression of retinopathy during pregnancy observed by us in women reaching an average $\mathrm{HbA} 1 \mathrm{c}$ of $5.6 \%$ from pregnancy week 20 is reassuring for continuing a strategy of strict metabolic control. ${ }^{8}$ Duration of DM \& progression of retinopathy in pregnant group for which $\mathrm{P}$ value is $>0.05$, nonsignificance. In Temple RC et al Progression of retinopathy was significantly increased in women with duration of diabetes 10-19 years compared with duration $<10$ years $(10 \%$ vs. $0 \% ; \mathrm{P}=0.007)$ 
and in women with moderate to severe background retinopathy at booking (30\% vs. $3.7 \% ; \mathrm{P}=0.01) .^{9}$ This contradiction study by Temple Rc et al, because of small sample size, few pregnant women $>10$ years. Age group 25-30 $\&>30$ years progression of retinopathy occur more frequently as the age progresses is $43.4 \%$ showed progression in $>30$ years as compared to $12.5 \%$ in $25-30$ age group $\mathrm{P}<0.05$, significant. So more is age more likely there is progression of retinopathy during pregnancy. Kostraba JN et al showed that young age at onset is a protective factor in the long term or whether it only delays the onset of proliferative retinopathy. ${ }^{10}$ BMI \& progression of retinopathy is non-significant as $\mathrm{P}>0.05$. $\mathrm{BMI}<24 \&>30$ there is progression of retinopathy but doesn't hold good in BMI group 25-29.99. In Klein BE et al study group, the prevalence of being obese was $25.2 \% .^{11}$

\section{Conclusion}

Diabetic retinopathy affects over one- third of all people with diabetes \& sss the leading cause of vision loss in working age adults. Maximum changes occurs during 24-30 weeks of gestation though accelerated progression may present throughout pregnancy. There should be proper collaboration between physician, gynecologists \& ophthalmologist regarding diabetic retinopathy management in pregnancy.

\section{References}

1. "About diabetes". World Health Organization. Archived from the original on 31March 2014. Retrieved 4 April 2014.

2. Diabetes Programme". World Health Organization. Archived from the original on 26 April 2014. Retrieved 22 April 2014.

3. Prediabetes \& Insulin Resistance. - The National Institute of Diabetes and Digestive and Kidney Diseases Health Information Center. Retrieved: March 01, 2017.
4. Impact of pregnancy on the progression of diabetic retinopathy in Type 1 diabetes. Temple RC, Aldridge VA, Sampson MJ, Greenwood RH, Heyburn PJ, Glenn A Diabet Med. $2001 \mathrm{Jul}$; 18(7):573-7.

5. Changes in diabetic retinopathy during pregnancy. Correlations with regulation of hyperglycemia. Phelps RL, Sakol P, Metzger BE, Jampol LM, Freinkel N. Arch Ophthalmol. 1986 Dec; 104(12):1806-10.

6. Temple RC, Aldridge VA, Sampson MJ. et al. Impact of pregnancy on the progression of diabetic retinopathy in Type I diabetes. Diabet Med. 2001;18((7)):573-7.

7. Mallika, PS et al. "Diabetic Retinopathy and the Effect of Pregnancy." Malaysian Family Physician : the Official Journal of the Academy of Family Physicians of Malaysia 5.1 (2010): 2-5.

8. Mathiesen ER, Vaz JA (2008) Insulin treatment in diabetic pregnancy. Diabetes Metab Res Rev 24:S3-S20.

9. Impact of pregnancy on the progression of diabetic retinopathy in Type 1 diabetes. Temple RC, Aldridge VA, Sampson MJ, Greenwood RH, Heyburn PJ, Glenn Diabet Med. 2001 Jul; 18(7):573-7.

10. Kostraba JN, Dorman JS, Orchard TJ, Becker DJ, Ohki Y, Ellis D, Doft BH, Lobes LA, LaPorte RE, Drash AL: Contribution of diabetes duration before puberty to development of microvascular complications in IDDM subjects. Diabetes Care 1989;12:686-693.

11. Klein R, Klein BE, Moss SE. Is obesity related to microvascular and macrovascular complications in diabetes? The Wisconsin Epidemiologic Study of Diabetic Retinopathy. Arch Intern Med. 1997 Mar 24; 157(6):650-6. PubMed PMID: 9080919. 